\title{
Genetic correlation between arsenate tolerance and the rate of influx of arsenate and phosphate in Holcus lanatus L.
}

\author{
ANDREW A. MEHARG \& MARK R. MACNAIR \\ Department of Biological Sciences, Hatherly Laboratories, University of Exeter, Prince of Wales Road, \\ Exeter EX4 4PS, U.K.
}

\begin{abstract}
Arsenate tolerant genotypes of Holcus lanatus L. possess an altered phosphate and arsenate uptake system such that the rate of influx of arsenate and phosphate is much lower in tolerant plants than in non-tolerant plants, especially at low arsenate concentrations. The rate of influx of both arsenate and phosphate was studied in segregating and non-segregating families derived from crosses between mine and non-mine plants. In non-segregating families, all progeny had low uptake of arsenate and phosphate; in segregating families non-tolerant plants had higher rates of arsenate and phosphate uptake than the tolerant plants. The altered phosphate (and arsenate) uptake system was genetically correlated to arsenate tolerance. The two characters may represent the pleiotropic effects of the same genes, or they may show very tight genetic linkage. In the absence of recombinants, the former explanation is preferred. These results are further evidence that reduced arsenate uptake is a mechanism of arsenate tolerance in $H$. lanatus.
\end{abstract}

Keywords: genetics, phosphate, tolerance, uptake mechanisms.

\section{Introduction}

Investigations into the mechanisms of metal tolerance in angiosperms have so far provided no more than a superficial understanding of tolerance (Bradshaw et al., 1990; Ernst et al., 1990; Verkleij \& Schat, 1990). A number of mechanisms have been postulated as being involved in metal tolerance. These fall into three broad categories, exclusion (avoidance or limited uptake of the metal), detoxification by subcellular compartimentalization or binding to cell walls and biochemical detoxification by specialized metabolic pathways and enzymatic adaptations (Berry, 1986). Many of these mechanisms fail to explain the metal specificity of the resistance in higher plants (Verkeij \& Schat, 1990). One of the major problems confronting researchers into the mechanisms of tolerance is the problem of linkage disequilibrium. Many studies have compared mine plants with non-mine plants, and thus are unable to distinguish primary tolerance mechanisms from secondary effects that may have spread in mine plants subsequent to the evolution of tolerance, and thus be in linkage disequilibrium with the tolerance gene(s). Only a genetic study in which recombination between the tolerance gene(s) and the putative mechanism is permitted can help to resolve this problem.

Meharg \& Macnair (1990, 1991a) determined that arsenate-tolerant Holcus lanatus $\mathrm{L}$. possessed an altered phosphate (and arsenate) uptake system, where the high affinity phosphate uptake system was suppressed. Arsenate behaved as a phosphate analogue and the uptake of both these ions was by the same uptake systems in both tolerant and non-tolerant plants. The rate of influx of these ions was much greater in excised roots of non-tolerant plants than in tolerant plants. It was proposed that this altered phosphate uptake system could be a mechanism of arsenate tolerance in this species. This mechanism was metalspecific and could be interpreted as a simple adaptation of the phosphate uptake transferase, providing a physiological basis for tolerance in $H$. lanatus. Differences in short-term influx of arsenate also explained differences in long-term uptake between the genotypes (Macnair \& Cumbes, 1987; Meharg \& Macnair, 1991a). The same differences in arsenate uptake have also been shown to occur in the arsenate tolerant grasses Deschampsia cespitosa and Agrostis capillaris (Meharg \& Macnair, 1991b). However, the phosphate 
status of the arsenic mine soils is low (A. A. Meharg unpublished data). Species adapted to areas of low nutrient status have reduced rates of ion influx (Chapin, 1980). It is therefore possible that the phenomenon of reduced arsenate uptake is not a mechanism of tolerance, but rather an adaptation to low nutrient status in linkage disequilibrium with tolerance. To show that reduced arsenate uptake may be the tolerance mechanism requires the demonstration that the two phenomena co-segregate in suitable crosses.

Arsenate tolerance has been shown to be inherited and under the control of a small number of genes in $A$. capillaris (Watkins \& Macnair, 1991) and by a major gene with variable penetrance in $H$. lanatus (Macnair et al., 1992), with tolerance being dominant. In this present study the genetic correlation between arsenate tolerance and the presence of the altered phosphate uptake system was investigated in $F_{2}$ and $F_{3}$ crosses between mine and non-mine plants of $H$. lanatus.

\section{Materials and methods}

\section{Plant material}

The crosses between tolerant and non-tolerant genotypes are described in the accompanying paper by Macnair et al. (1992) (hereafter referred to as MCM). A number of different families were selected to investigate if the altered phosphate uptake system co-segregated with arsenate tolerance. These crosses included families in which the female parent had been either heterozygous or homozygous for arsenate tolerance. Because tolerance is dominant, heterozygous females will produce segregating families, while homozygous females will produce families non-segregating for tolerance. To avoid complex family provenances confusing this paper, all families used here have been renumbered 1-13; Table 1 lists these families and relates them to the corresponding families in MCM.

Plants were tested for tolerance as seedlings and then pricked out into pots of John Innes compost and grown in a greenhouse until sufficient tillers were available for tolerance testing as adults and the determination of phosphate and/or arsenate influx.

The different families analysed here were grown on different occasions, and tested in different experiments. However, in all cases the various plants within a family were grown together in randomized blocks and all rooting and uptake tests conducted within a single experiment.

\section{Rooting tests}

Rooting tests for both seedlings and tillers are described in MCM. They involved determining the
Table 1 Provenance of the 13 families used in the experiments described in this paper

\begin{tabular}{rll}
\hline Family & $\begin{array}{l}\text { Maternal } \\
\text { genotype }\end{array}$ & Provenance \\
\hline 1 & $T t$ & C19 $\times$ G2 packet 3 (table 3, MCM) \\
2 & $T t$ & C20 $\times$ C19 packet 3(table 3, MCM) \\
3 & $T t$ & G21 ext plant 5 (table 4, MCM) \\
4 & $T t$ & G21 ext plant 10 (table 4, MCM) \\
5 & $T t$ & C20 $\times$ G12 packet 3 (table 3, MCM) \\
6 & $T t$ & G21 ext plant 8 (table 4, MCM) \\
7 & $T t$ & G21 exp plant 13 (table 4, MCM) \\
8 & $T T$ & C20 $\times$ C19/1 plant 2 (table 5, MCM) \\
9 & $T t$ & C19 $\times$ G2/1 plant 2 (table 5, MCM) \\
10 & $T t$ & C20 $\times$ C19/1 plant 6 (table 5, MCM) \\
11 & $T t$ & C19 $\times$ G2/1 plant 7 (table 5, MCM) \\
12 & $T T$ & G21 ext plant 7 (table 4, MCM) \\
13 & $T T$ & G21 ext plant 17 (table 4, MCM) \\
\hline
\end{tabular}

length of the longest root of seedlings and tillers grown for 1 week in nutrient solution containing $0.133 \mathrm{~mol}$ $\mathrm{m}^{-3}$ arsenate in the absence of phosphate. All tolerance tests reported here used the tiller method to test adult plants.

\section{Determination of the rate of phosphate and arsenate influx}

In all experiments unrooted-tillers were placed in phosphate-free nutrient solution $\left(0.2 \mathrm{ml} \mathrm{m}^{-3} \mathrm{Ca}\right.$ $\left(\mathrm{NO}_{3}\right)_{2}, 0.2 \mathrm{~mol} \mathrm{~m}^{-3} \mathrm{KNO}_{3}, 0.1 \mathrm{~mol} \mathrm{~m}^{-3} \mathrm{MgSO}_{4}$ ) for 7 days. Tillers were rooted under a light bank with a $16 \mathrm{~h}$ day length in a single $12 \mathrm{dm}^{3}$ container (containing $10 \mathrm{dm}^{3}$ of nutrient solution): this had a lid with 240 tubes to hold the tillers.

Stock solutions of arsenate were prepared by dissolving $\mathrm{Na}_{2} \mathrm{HAsO}_{4} \cdot 7 \mathrm{H}_{2} \mathrm{O}$ in distilled water. All the test solutions contained the phosphate-free nutrient solution, and test solutions were adjusted to $\mathrm{pH} 5$ using dilute $\mathrm{HCl}$ because phosphate uptake is $\mathrm{pH}$ dependent (Meharg \& Macnair, 1991a). In experiments to determine phosphate influx, $\left[{ }^{32} \mathrm{P}\right.$ ) (as $\mathrm{NaH}_{2} \mathrm{PO}_{4}$, supplied by Amersham) was added to the phosphate-free nutrient solution to give the required concentration.

To determine arsenate and phosphate influx, roots (excised at the node for arsenate uptake and $20-\mathrm{mm}$ root tip segments for phosphate uptake) were incubated in $10 \mathrm{~cm}^{3}$ and $2 \mathrm{~cm}^{3}$ of test solution respectively for $20 \mathrm{~min}$ at room temperature. Uptake was terminated with an ice-cold rinse in nutrient solution containing $1 \mathrm{~mol} \mathrm{~m}^{-3} \mathrm{Na}_{2} \mathrm{HPO}_{4}$. The roots were then incubated for a further $10 \mathrm{~min}$ in a solution of the same composition as that used in the rinse to ensure desorption of $\left.{ }^{32} \mathrm{P}\right]$ or arsenate from the root-free space. Fresh weights of the roots were determined before analysis. 


\section{Analysis}

To determine ${ }^{32} \mathrm{PO}_{4}^{3-}$ uptake, fresh roots were placed in $20 \mathrm{~cm}^{3}$ glass scintillation vials, to which $1 \mathrm{~cm}^{3}$ of tissue solubilizer (Soluene-350, Packard) was added and the $\left[{ }^{32} \mathrm{P}\right]$ activity in the roots determined against quenched standards using a Packard Tri-Carb 460 CD liquid scintillation counter.

Arsenic was determined by digesting the roots in $2 \mathrm{~cm}^{3}$ concentrated nitric acid (Aristar grade). Samples were digested by heating on a block digester for $1 \mathrm{~h}$ at $180^{\circ} \mathrm{C}$ and then $1 \mathrm{~h}$ at $200^{\circ} \mathrm{C}$, to evaporate the samples to dryness. The residue was taken up in $10 \mathrm{~cm}^{3}$ of 5 per cent v/v HCl (Analar grade) containing $20 \mathrm{~mol} \mathrm{~m}^{-3} \mathrm{KI}$. Arsenic was then determined by a hydride generation technique using a Philips PU9060 continuous flow vapour system which was interfaced with a Philips SP9 series atomic absorption spectrophotometer.

\section{Results}

The short-term uptake of mineral ions generally follows Michaelis-Menten kinetics. Figure 1 plots the rate of uptake of arsenate against concentration for a tolerant and non-tolerant clone, two of the original parents of the crossing programme which generated the remaining families used in this paper. The very great difference in uptake at low external concentrations means that it is possible to investigate the genetic

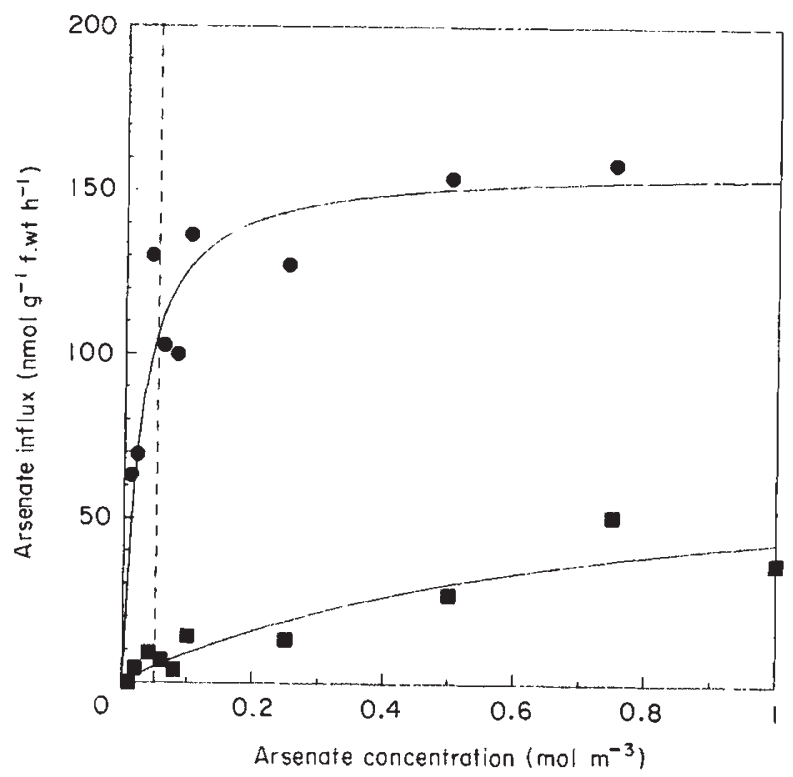

Fig. 1 Typical arsenate uptake isotherm for tolerant $(\boldsymbol{\square})$ and non-tolerant $(\bullet)$ clones. Each point is the mean of six independent replicates. The vertical dotted line illustrates the concentration of arsenate at which all other uptake studies were performed. correlation between tolerance and reduced uptake by testing the uptake of arsenate or phosphate at a single concentration (the concentration of arsenate used has been indicated on Fig. 1).

The short-term influx of phosphate and arsenate into tolerant and non-tolerant plants of segregating families is given in Table 2 (phosphate) and Table 3 (arsenate). In every case, on average the tolerant plants have lower influx of phosphate or arsenate, and in all but two cases the difference is significant. The tolerant

Table 2 The mean values $( \pm$ S.E. $)$ of short-term $(20 \mathrm{~min})$ phosphate influx in excised roots of tolerant and nontolerant siblings from segregating families of $H$. lanatus. In each case five or six plants were tested. The significance of the $t$-test testing for equality of the means is also given

\begin{tabular}{llll}
\hline & \multicolumn{2}{l}{ Influx $\left(\mathrm{nmol} \mathrm{g}^{-1}\right.$ f.wt. $\left.\mathrm{h}^{-1}\right)$} \\
\cline { 2 - 4 } Family & Tolerant & Non-tolerant & \\
\hline $1 \dagger$ & $25.8 \pm 4.9$ & $79.6 \pm 16.2$ & $* *$ \\
$2 \dagger$ & $45.7 \pm 14.2$ & $86.7 \pm 16.9$ & $*$ \\
$3 \ddagger$ & $20.8 \pm 3.9$ & $32.8 \pm 7.2$ & ns \\
$4 \ddagger$ & $8.8 \pm 3.1$ & $38.9 \pm 16.5$ & $*$ \\
$5 \ddagger$ & $11.5 \pm 2.9$ & $30.6 \pm 6.5$ & $* *$ \\
\hline
\end{tabular}

The rate of phosphate uptake was determined using $\left[{ }^{32} \mathrm{P}\right]$ (as $\mathrm{NaH}_{2} \mathrm{PO}_{4}$ ) at a concentration of $\uparrow 0.01 \mathrm{~mol} \mathrm{~m}^{-3}$ of $\ddagger 0.005$ $\mathrm{mol} \mathrm{m}^{-3}$.

ns $=$ non-significant ${ }^{*} P<0.05 ; * * P<0.01$.

Table 3 The mean values of short-term $(20 \mathrm{~min})$ influx of $0.05 \mathrm{~mol} \mathrm{~m}^{-3}$ arsenate in excised roots of siblings from segregating and non-segregating families

\begin{tabular}{|c|c|c|c|c|c|}
\hline \multirow[b]{2}{*}{ Family } & \multicolumn{5}{|c|}{ Influx (nmol $g^{-1}$ f.wt. $\left.h^{-1}\right)$} \\
\hline & Tolerant & $n$ & Non-tolerant & $n$ & \\
\hline \multicolumn{6}{|c|}{ Segregating families } \\
\hline 1 & $16.8 \pm 6.0$ & 5 & $45.9 \pm 13.1$ & 5 & $*$ \\
\hline 2 & $44.3 \pm 6.1$ & 5 & $61.6 \pm 19.5$ & 5 & ns \\
\hline 3 & $49.4 \pm 2.4$ & 18 & $93.0 \pm 9.4$ & 20 & $* * *$ \\
\hline 6 & $22.1 \pm 2.5$ & 12 & $132.6 \pm 26.1$ & 5 & $* * *$ \\
\hline 7 & $21.5 \pm 2.5$ & 15 & $74.6 \pm 17.8$ & 4 & $* * *$ \\
\hline 9 & $43.8 \pm 4.5$ & 27 & $70.8 \pm 7.2$ & 23 & $* *$ \\
\hline 10 & $40.8 \pm 5.8$ & 15 & $83.5 \pm 10.5$ & 21 & $* *$ \\
\hline 11 & $32.4 \pm 3.3$ & 24 & $58.0 \pm 4.5$ & 20 & $* * *$ \\
\hline \multicolumn{6}{|c|}{ Non-segregating families } \\
\hline 8 & $31.0 \pm 5.6$ & 23 & $63.2 \pm 16.4$ & 9 & * \\
\hline 12 & $29.3 \pm 5.1$ & 11 & $19.5 \pm 3.4$ & 6 & ns \\
\hline 13 & $23.8 \pm 3.3$ & 17 & $12.3 \pm 6.7$ & 2 & ns \\
\hline
\end{tabular}

$\mathrm{n}=$ the number of plants tested.

ns $=$ non-significant $;{ }^{*} P<0.05 ;{ }^{* *} P<0.01 ;{ }^{* * *} P<0.001$. 
plants must, therefore, have reduced influx rates of these ions, although there are considerable between-family differences in the overall rates of uptake. These results show clearly that there is an association between tolerance and reduced ion uptake. The pattern of co-segregation of the two characters is examined in more detail in Fig. 2, in which the influx of arsenate is plotted against root length in arsenate solution (a measure of tolerance) for every plant from the eight segregating families. It is clear that all plants that score as tolerant to arsenate (with root lengths of more than $30-40 \mathrm{~mm}$ ) have low rates of arsenate influx. All those with high rates are non-tolerant by the rooting test. There are, however, many non-tolerants that also have low uptake rates, as low as the tolerants.

In the case of the three families where the maternal parent was postulated to be homozygous for the tolerance gene, in only one of the three families did the nontolerant plants have a higher rate of uptake than the tolerant plants (Table 3). The pattern of co-segregation of the two characters is shown in Fig. 3, where it can be seen that all plants have low uptake rates, except for four plants from family 8 . This family was the family which had the lowest repeatibility of tolerance testing (MCM, Table 6).

\section{Discussion}

In previous papers (Meharg \& Macnair, 1990, 1991a,b) we have shown that arsenate tolerant plants of Holcus lanatus, Deschampsia cespitosa and Agrostis capillaris all show reduced short-term influx of arsenate, particularly at low substate concentrations. The influx isotherms of inorganic ions can be represented by the sum of two Michaelis-Menten equations (Epstein, 1976). This observation is generally interpreted as being caused by the presence of two independent uptake systems: a high-affinity uptake system that saturates at low substrate concentrations, and a low-affinity system saturating at higher concentrations. We postulated that arsenate tolerance could have been achieved by the suppression, or alteration of the highaffinity uptake system in these plants.

However, it has been shown that plants growing in soils with low nutrient status also have reduced ion uptake (Chapin, 1980), and because mines typically have low levels of most essential nutrients, it is possible that the differences in phosphate uptake observed have nothing to do with tolerance per se. In addition, other hypotheses, such that the difference in phosphate uptake is a secondary mechanism, are possible. Purely
Fig. 2 The relationship between tolerance, as determined by tiller root growth in arsenate, and arsenate influx at $0.05 \mathrm{~mol} \mathrm{~m}^{-3}$ arsenate in the progeny from all the segregating families studied here.

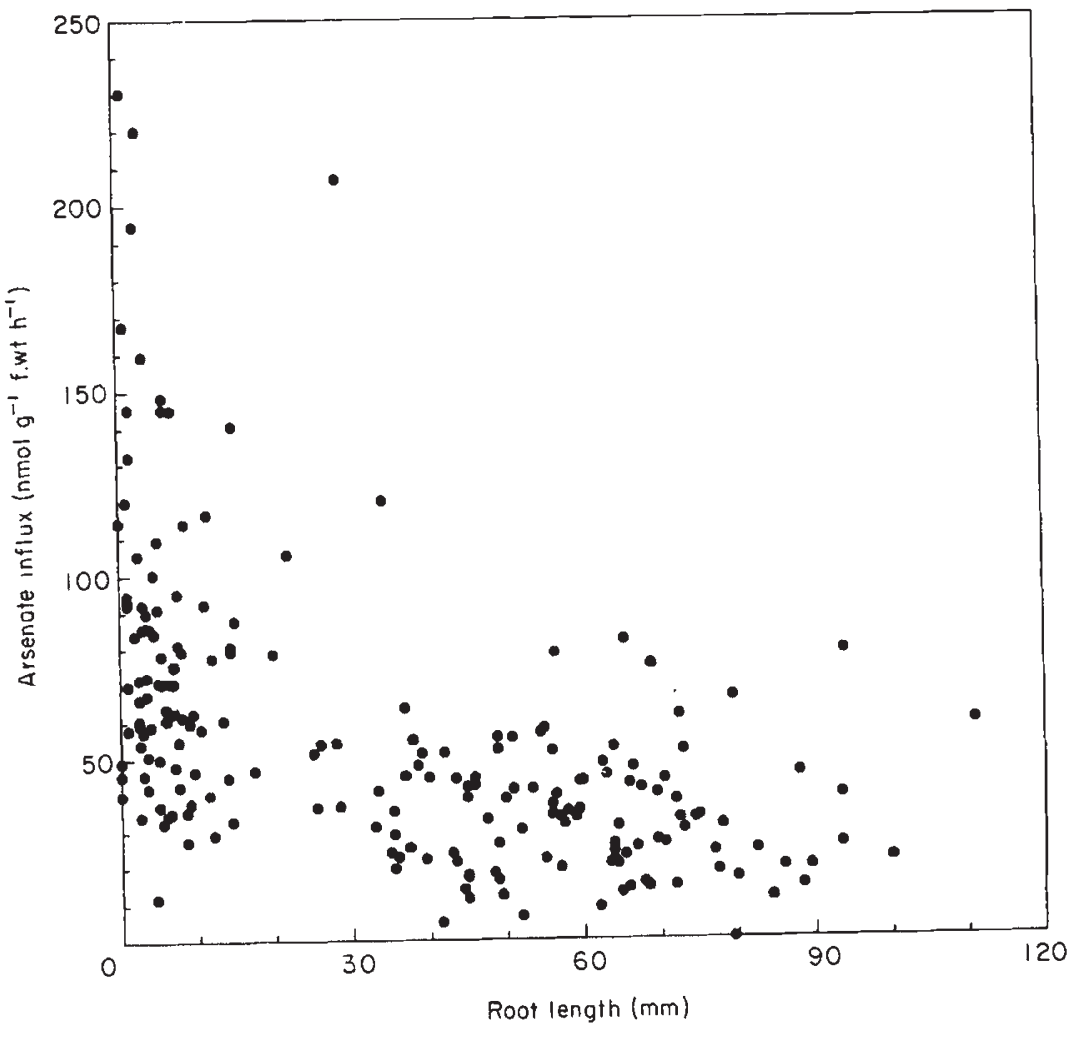




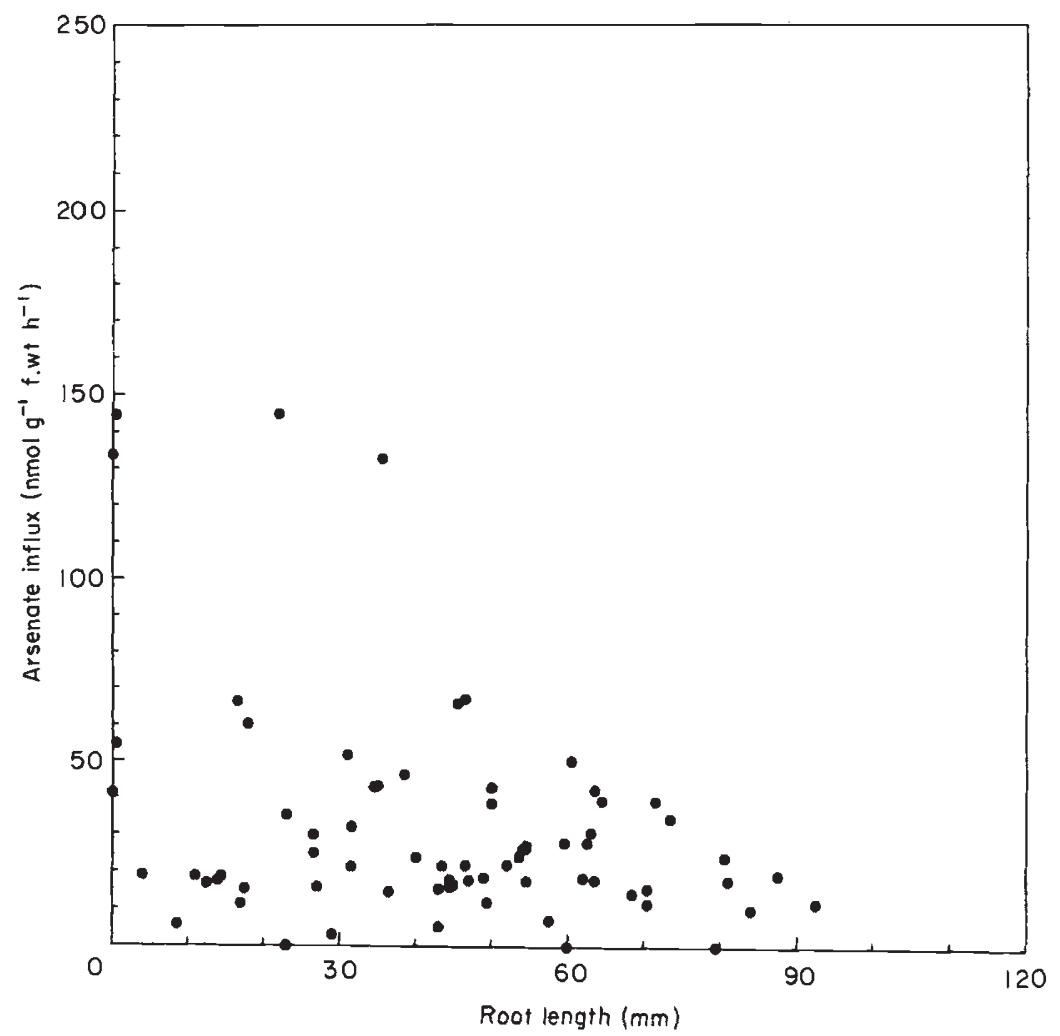

Fig. 3 The relationship between tolerance, as determined by tiller root growth in arsenate, and arsenate influx at $0.05 \mathrm{~mol} \mathrm{~m}^{-3}$ arsenate in non-segregating families. phenotypic studies are unable to distinguish these possible hypotheses. If, however, the two characters cosegregate in suitable crosses, then there is much stronger evidence that the alterations to the phosphate uptake system are indeed involved in the arsenate tolerance mechanism of $H$. lanatus.

The results presented here clearly show co-segregation of the two characters. In families segregating for tolerance, all tolerant plants show reduced arsenate influx, while non-tolerant plants, on average, show higher rates of influx. In families that do not segregate for tolerance, almost all plants show reduced influx. However, some non-tolerant plants also show reduced influx. If both characters are pleiotropic effects of the same gene, and both show complete penetrance, then these latter plants should not exist. There are a number of possible explanations for them.

(a) Recombination. If the two characters are determined by independent genes, then one would expect these individuals in the $\mathrm{F}_{2}$ by recombination. However, one would also expect the other recombinants, tolerant plants with low uptake. Figures 2 and 3 show that these plants are not found in these families. This explanation can therefore be excluded.

(b) Environmental suppression of the high uptake character. The degree of expression of the phosphate uptake system is dependent on the plant phosphate status (Clarkson et al., 1978). We have shown (Meharg \& Macnair, 1992) that pretreating non-tolerant plants with phosphate leads to a suppression of the phosphate uptake system to a level comparable with that of tolerant plants; a similar treatment applied to tolerants has very little effect. Minor differences in the condition of plants before they were tested could cause non-tolerant plants to show suppression of the phosphate uptake system; obviously if the system is absent or constitutively suppressed in tolerant plants then they would be less susceptible to environmental variation. It is therefore expected under the hypothesis being tested that the non-tolerants would show greater variation in arsenate uptake than tolerants.

(c) Incomplete penetrance of the tolerance gene. In the accompanying paper, Macnair et al. (1992) present evidence that there is a major gene for arsenic tolerance but that the gene does not always show complete penetrance. There is evidence that the degree of penetrance depends on the genetic background, and some of the families showing relatively low penetrance were included in the experiments reported here. If the two characters are genetically associated, but the tolerance character shows incomplete penetrance, then non-tolerant, low uptake plants are to be expected to be present. 
The data, therefore, clearly indicate that the two characters co-segregate. There are two possible causes for this genetic correlation. Firstly, the characters could be pleiotropic manifestations of the same gene; alternatively, the genes could be tightly linked. This latter hypothesis obviously cannot be discounted, but the degree of linkage required had to be high in view of the absence of tolerant high-uptake recombinants in Fig. 2 . In the absence of further data, the simpler hypothesis is preferred. These data therefore support the hypothesis advanced on the basis of the comparison of tolerant and non-tolerant clones (Meharg \& Macnair, 1990, $1991 \mathrm{a}, \mathrm{b})$, that the primary mechanism for arsenate tolerances is the reduced rate of uptake of the toxic ion.

However, the variable penetrance of the tolerance gene suggests that although the altered phosphate uptake system is a mechanism of arsenate tolerance it may not be sufficient to explain tolerance in itself. Reduced uptake of a toxic ion will alleviate toxicity but arsenate is still being taken up by the plant, albeit at a much lower rate, and tolerant plants can accumulate considerable levels of arsenate (Porter \& Peterson, 1975, 1977; Benson et al., 1981a; Meharg \& Macnair, 1991a). Mechanisms of intracellular detoxification of arsenate have been postulated (Benson et al., 1981b; Benson, 1984). If these mechanisms are limited to, or more efficient in, tolerant plants, then it may be that other mechanisms will prove to be necessary as well as reduced influx. The evidence presented here, however, that all tolerant plants have the reduced uptake, suggests that if these other processes do exist, then they depend on the reduced influx of arsenate (produced by the gene studied here) to be able to function and detoxify the arsenate. Further research is required to investigate these possibilities.

\section{Acknowledgements}

This research was funded by SERC grant no. GR/ F18947 to MRM, the receipt of which is gratefully acknowledged. We thank Quinton Cumbes for help with some of the tolerance tests.

\section{References}

BENSON, A. A. 1984. Arsenic and new lace. In: Randal, D. D., Blevins, D. G., Lawson, R. L. and Rapp, B. J. (eds) Current Topics in Plant Biochemistry and Physiology, Vol. 3, University of Missouri-Columbia Press, MI, USA. pp. 149-153.

BENSON, A. A., COONEY, R. v. AND HERRERA-LASSO, J. M. $1981 \mathrm{a}$. Arsenic metabolism in algae and higher plants. J. Plant Nutr., 3, 285-292.

BENSON, L. M., PORTER, E. K. AND PETERSON, P. J. 1981b. Arsenic accumulation and genotypic variation in plants on arsenical mine wastes in S.W. England. J. Plant Nutr., 3, 655-666.

BERRY, W. L. 1986. Plant factors influencing the use of plant analysis as a tool for biogeochemical prospecting. In: Carlisle, D., Berry, W. L., Kaplan, I. R. and Watterson, J. R. (eds) Mineral Exploration: Biogeochemical Systems and Organic Matter, Vol. 5, Prentice-Hall, NJ, p. 13.

BRADShAW, A. D., MCNEILly, T. AND PUTWAIN, P. D. 1990. The essential qualities. In: Shaw. A. J. (ed.) Heavy Metal Tolerances in Plants: Evolutionary Aspects, CRC Press, FL, pp. 323-334.

CHAPIN, F. S. 1980 . The mineral nutrition of wild plants. Ann. Rev. Ecol. Syst., 11, 233-260.

CLARKSON, D. T., SANDERSON, J. AND SCATTERGOOD, C. B. 1978. Influence of phosphate stress on phosphate absorption and translocation by various parts of the root system of Hordeum vulgare L. (Barley). Planta, 139, 47-53.

EPSTEIN, E. 1976. Kinetics of ion transport and the carrier concept. In: Lüttge, U. and Pitman, M. G. (eds) Transport in Plants II. Part B, Tissues and Organs, Encyclopedia of Plant Physiology, New Series, Vol. 2, Springer-Verlag, Berlin, pp. 70-94.

ERNST, W. H. O., SCHAT, H. AND VERKLEIJ, J. A. C. 1990. Evolutionary biology of metal resistance in Silene Vulgaris. Evol. Trends Plants, 4, 45-51.

MACNAIR, M. R. AND CUMBES, Q. 1987. Evidence that arsenic tolerance in Holcus lanatus $\mathrm{L}$. is caused by an altered phosphate uptake system. New Phytol., 107, 387-394.

MACNAIR, M. R., CUMBES, Q. AND MEHARG, A. A. 1992. The genetics of arsenate tolerance in Yorkshire fog, Holcus lanatus L. Heredity, 69, 325-335.

MEHARG, A. A. AND MACNAIR, M. R. 1990. An altered phosphate uptake system in arsenate tolerant Holcus lanatus. New Phytol., 16, 29-35.

MEHARG, A. A. AND MACNAIR, M. R. 1991a. Uptake, accumulation and translocation of arsenate in arsenate tolerant and non-tolerant Holcus lanatus L. New Phytol., 117, 225-231.

MEHARG, A. A. AND MACNAIR, M. R. 1991b. Mechanisms of arsenate tolerance in Deschampsia cespitosa L. (Beauv.) and Agrostis capillaris L., Adaptation of the arsenate uptake system. New Phytol., 119, 291-297.

MEHARG, A. A. AND MACNAIR, M. R. 1992. Suppression of the high affinity phosphate uptake system: a mechanism of arsenate tolerance in Holcus lanatus L. J. Exp. Bot. 43, 519-524.

PORTER, E. K. AND PETERSON, P. J. 1975. Arsenic accumulation by plants on mine waste (United Kingdom). Sci. Tot. Env., 4, 365-371.

PORTER, E. K. AND PETERSON, P. J. 1977. Arsenic tolerance in grasses growing on mine waste. Environ. Poll., 14, $255-265$.

VERKLEIJ, J. A. C. AND SCHAT, H. 1990. Mechanisms of metal tolerance in higher plants. In: Shaw, A. J. (ed.) Heavy Metal Tolerances in Plants: Evolutionary Aspects, CRC Press, FL, pp. 179-193.

WATKINS, A. D. AND MACNAIR, M. R. 1991. Genetics of arsenic tolerance in Agrostis capillaris L. Heredity, 66, 47-54. 